\title{
Monophasic Synovial Sarcoma
}

National Cancer Institute

\section{Source}

National Cancer Institute. Monophasic Synovial Sarcoma. NCI Thesaurus. Code C6534.

A synovial sarcoma characterized by the presence of an epithelial or a spindle cell

component only. 